\title{
Different Outcomes of Experimental Hepatitis E Virus Infection in Diverse Mouse Strains, Wistar Rats, and Rabbits
}

\author{
Josephine Schlosser ${ }^{1,+}{ }^{\text {, Lisa Dähnert }}{ }^{1}$, Paul Dremsek ${ }^{1, \ddagger}$, Kerstin Tauscher ${ }^{2, \S}$, Christine Fast ${ }^{1}$, \\ Ute Ziegler $^{1}$, Albrecht Gröner ${ }^{3}$, Rainer G Ulrich ${ }^{1,4}$, Martin H Groschup ${ }^{1,4}$ and Martin Eiden ${ }^{1, *}$ (D) \\ 1 Institute of Novel and Emerging Infectious Diseases, Friedrich-Loeffler-Institut, \\ 17493 Greifswald-Insel Riems, Germany; josephine.schlosser@gmx.de (J.S.); lisa.daehnert@fli.de (L.D.); \\ p.dremsek@labormustafawien.at (P.D.); Christine.fast@fli.de (C.F.); ute.ziegler@fli.de (U.Z.); \\ Rainer.ulrich@fli.de (R.G.U.); martin.groschup@fli.de (M.H.G.) \\ 2 Department of Experimental Animal Facilities and Biorisk Management, Friedrich-Loeffler-Institut, \\ Südufer 10, 17493 Greifswald-Insel Riems, Germany; kerstin_tauscher@gmx.de \\ 3 PathoGuard Consult, 64342 Seeheim-Jugenheim, Germany; info@patho-guard.com \\ 4 German Center for Infection Research (DZIF), partner site Hamburg-Lübeck-Borstel, \\ 17493 GreifswaldInsel Riems, Germany \\ * Correspondence: martin.eiden@fli.de; Tel.:+49-38351-71182 \\ † Present address: Institute for Immunology, Centre for Infection Medicine, Freie Universität Berlin, \\ 14163 Berlin, Germany. \\ $\ddagger \quad$ Present address: Medical laboratory, Labor Doz. Dr. Stefan Mustafa, 1030 Wien, Austria. \\ $\S$ Present address: Specialist department for veterinary and food control, District Ludwigslust-Parchim, \\ 19288 Ludwigslust, Germany.
}

Received: 30 October 2018; Accepted: 19 December 2018; Published: 20 December 2018

\begin{abstract}
Hepatitis E virus (HEV) is the causative agent of acute hepatitis E in humans in developing countries, but autochthonous cases of zoonotic genotype 3 (HEV-3) infection also occur in industrialized countries. In contrast to swine, rats, and rabbits, natural HEV infections in mice have not yet been demonstrated. The pig represents a well-established large animal model for HEV-3 infection, but a suitable small animal model mimicking natural HEV-3 infection is currently missing. Therefore, we experimentally inoculated C57BL/ 6 mice (wild-type, IFNAR ${ }^{-/}, \mathrm{CD}^{-/-}, \mathrm{CD}^{-/-}$) and BALB/c nude (nu/nu) mice, Wistar rats, and European rabbits with a wild boar-derived HEV-3 strain and monitored virus replication and shedding, as well as humoral immune responses. HEV RNA and anti-HEV antibodies were detected in one and two out of eight of the rats and all rabbits inoculated, respectively, but not in any of the mouse strains tested. Remarkably, immunosuppressive dexamethasone treatment of rats did not enhance their susceptibility to HEV infection. In rabbits, immunization with recombinant HEV-3 and ratHEV capsid proteins induced protection against HEV-3 challenge. In conclusion, the rabbit model for HEV-3 infection may serve as a suitable alternative to the non-human primate and swine models, and as an appropriate basis for vaccine evaluation studies.
\end{abstract}

Keywords: Hepatitis E virus; genotype 3; wild boar; mouse; rat; rabbit; knockout mouse; BALB/c; C57BL/6; animal model

\section{Introduction}

Hepatitis E virus (HEV) is the causative agent of hepatitis E in humans and taxonomically classified in the family Hepeviridae. It is a small, quasi-enveloped virus with a single-stranded RNA genome of positive polarity [1-3]. The virus can cause large epidemics, especially in developing countries, where the virus is primarily transmitted via the fecal-oral route through contaminated water due to poor sanitation [4]. 
However, emerging cases of sporadic and autochthonous hepatitis E also occur in industrialized countries, including the USA, Japan, and European countries [5]. Recently, several hepeviruses were identified in different mammals, such as rodents, bats, camels, carnivores, and moose. Additionally, more distantly related viruses were discovered in chicken and fish [6,7]. A consensus taxonomy has recently been published which divides the family Hepeviridae into two genera designated Orthohepevirus, including four species named Orthohepevirus $A$ to $D$, and the genus Piscihepevirus [8]. Within the species Orthohepevirus $A$, human associated strains were grouped, namely genotypes 1 and 2 (HEV-1, HEV-2) that are restricted to humans and the zoonotic genotypes 3, 4 and 7 (HEV-3, HEV-4, HEV-7) that have been detected in domestic pig, wild boar, deer, and camels [7]. HEV-3-related strains were identified in European rabbits (Oryctolagus cuniculus) at multiple locations in the USA [9]; China [10]; and Europe, e.g., France [11] or Germany [12,13]. In Europe and Asia, food-borne zoonotic transmissions of HEV have been primarily associated with domestic pigs, wild boar, and deer as one of the main routes of human autochthonous infections [14-16]. In addition to the consumption of contaminated raw or undercooked meat, direct contact with pigs has to be considered as a risk factor for HEV infection [17,18]. Initially, HEV was thought to cause only acute courses, but especially HEV-3 strains are now known to be responsible for chronic hepatitis in immunocompromised patients and associated with extrahepatic manifestations [18-20].

Pigs, being the natural host species for HEV-3 and HEV-4, can be used as a homologous animal model system for HEV studies [21,22]. Laboratory mice and rats have also been explored as potential animal models for HEV. Although an earlier study indicated the susceptibility of Wistar rats to HEV-1 infection [23], recent trials aiming to infect Wistar rats with HEV-1 or HEV-2 failed [24,25]. Moreover, experiments to infect laboratory rats with HEV-3 were also not successful [24-26]. Injection of transcripts of a HEV-4 cDNA into the liver of rats led to a transient seroconversion [27]. This genotype was also shown to be infectious for BALB/c nude mice [28]. Another study in C57BL/ 6 mice demonstrated that animals intravenously inoculated with HEV-1 to HEV-4 were not susceptible to HEV [29]. Recently, a new liver chimeric mouse model was established in which human hepatocytes that were susceptible to HEV-1 and HEV-3 infection were transplanted [30]. Furthermore, experimental inoculation of rabbits with HEV-3 and HEV-4 strains resulted in seroconversion, but virus shedding and viremia were exclusively assigned to the HEV-4 strain used [30]. Experimental inoculation of rabbits with rabbit HEV led to seroconversion, fecal virus shedding, viremia, and elevated liver enzyme levels [31,32], and could result in chronic infections [33]. Pigs and macaques inoculated with rabbit HEV strains developed transient viremia and virus shedding, thus indicating the zoonotic potential of the virus [34,35].

Currently, experimental studies on pig- and wild boar-derived HEV-3 strains in rodents and rabbits are missing. As recently shown, HEV-3 infection in European wild boar (Sus scrofa scrofa) is naturally and experimentally transmissible to domestic pigs (Sus scrofa domestica), causing a variable degree of hepatic lesions [36]. As HEV has the ability to cross species barriers, it is important to prove the possibility of cross-species transmission between wild boar and rodents, and lagomorphs, i.e., rabbits. Establishing a small animal model (e.g., in immunodeficient mice) mimicking natural HEV-3 infection would be helpful to gain a better understanding of disease, as this may provide novel mechanistic insights into HEV replication and host immune defense to infection, which is limited in large animal models like the pig. Therefore, we experimentally inoculated C57BL/ 6 mice (wild-type, $\mathrm{IFNAR}^{-/-}, \mathrm{CD}^{-/-}, \mathrm{CD}^{-/-}$) and BALB/c nude mice, Wistar rats, and rabbits with HEV-3. To determine their susceptibility to HEV infection, viral replication and shedding, as well as the humoral immune response, were monitored. In addition, we also assessed whether dexamethasone treatment has an effect upon the susceptibility of rats to HEV-3 infection. Finally, the protective potential of recombinant HEV vaccine candidates was evaluated exemplarily in rabbits challenged by HEV-3 inoculation. 


\section{Materials and Methods}

\subsection{Inocula}

The HEV-3 strain used in this study originated from a liver sample of a naturally infected wild boar hunted in Northern Germany (Mecklenburg-Western Pomerania) in 2009, subtype 3b (accession number: JQ807477.1). The preparation of the liver suspension was performed as described before [36]. The inoculum contained about $2.0 \times 10^{4} \mathrm{HEV}$ RNA copies per $\mu \mathrm{L}$ RNA [cop/ $\mu \mathrm{L}$ ], as shown by RT-qPCR. Additionally, bile $\left(1.1 \times 10^{4} \mathrm{cop} / \mu \mathrm{L}\right)$ and feces $\left(3.1 \times 10^{3} \mathrm{cop} / \mu \mathrm{L}\right)$ of intravenously HEV-3 infected wild boar were used for the inoculation of different mouse strains. The corresponding genome numbers per $\mathrm{ml}$ are $7.3 \times 10^{6}$ (liver homogenate, Supplemental Figure S1), $2.9 \times 10^{6}$ (bile), and $1.1 \times 10^{6}$ (feces). In doing so, bile was diluted in phosphate-buffered saline (PBS; 20\%, w/v), sterile-filtered $\left(0.22 \mu \mathrm{m}\right.$ MILLEX ${ }^{\circledR}$ GP filter unit), and aliquoted in volumes of $2.5 \mathrm{~mL}$ and stored at $-70{ }^{\circ} \mathrm{C}$. Feces was suspended in PBS at a proportion of $20 \%(w / v)$. The fecal suspension was transferred to a $15 \mathrm{~mL}$ tube and mixed for $1 \mathrm{~min}$ using a vortex mixer. After centrifugation (20 min at $4000 \times g$ at $\left.4{ }^{\circ} \mathrm{C}\right)$, the supernatant was transferred to a new tube and filtered $\left(0.22 \mu \mathrm{m}\right.$ MILLEX ${ }^{\circledR} \mathrm{GP}$ filter unit). The suspension was aliquoted in volumes of $2.5 \mathrm{~mL}$ and stored at $-70{ }^{\circ} \mathrm{C}$.

\subsection{Animals and Experimental Design}

Wild-type, type I interferon receptor knockout mice (IFNAR ${ }^{-/-}$, B6-129Sv/Ev-IFNabRtm Agt), CD4 ${ }^{-/-}$(B6-CD4tm1 Mak) and CD8 ${ }^{-/-}$(B6-CD8atm1 Mak) mouse strains with the genetic background of C57BL/6 mice (Mus musculus) were bred in the specific-pathogen-free (SPF) breeding unit of the Friedrich-Loeffler-Institut, Insel Riems, Germany. The athymic BALB/c nude (nu/nu) mice (Mus musculus; CAnN.Cg-Foxn $1^{\text {nu }} / \mathrm{Crl}$, homozygous) were obtained from Charles River Laboratories, Sulzfeld, Germany. Female Wistar rats (Rattus norvegicus; Wistar RccHan ${ }^{\mathrm{TM}}$ ) were purchased from Harlan Laboratories, Venray, The Netherlands. Adult European rabbits were obtained from the quarantine and breeding facility of the Friedrich-Loeffler-Institut, Insel Riems, Germany. The experiments were approved by the competent authority of the Federal State of Mecklenburg-Western Pomerania, Germany, on the basis of national and European legislation, namely the EU council directive 86/609/EEC for the protection of animals used for experiments (LALLF M-V/TSD/7221.3-2.1.-014/10). Prior to the start of the experiments, all animals were shown to be negative for anti-HEV antibodies in serum and/or HEV RNA in feces, respectively. Following an initial clinical examination, all animals were allowed to get accustomed to the new surroundings for approximately one to two weeks prior to the initiation of experiments. All animals, except the BALB/c $\mathrm{nu} / \mathrm{nu}$ mice, were fed with commercial feed and had access to water ad libitum. The experiments were carried out under biosafety level $3^{* *}$ conditions. The isolator-maintained BALB/c nu/nu mice were kept in an SPF area including autoclaved feed and drinking water.

In general, blood and fecal samples were collected at consecutive time points every two to four days during the time course of the experiment and at necropsy and analysed once with the corresponding method. Additionally, rectal temperatures were measured in Wistar rats and rabbits.

Aliquots of serum samples were stored at $-20{ }^{\circ} \mathrm{C}$ for antibody detection. Fecal samples were diluted in isotonic saline solution $(10 \%, w / v)$ and stored at $-70{ }^{\circ} \mathrm{C}$ for RNA extraction. Animals were euthanized by exsanguination under anesthesia and samples were collected from their liver, gall bladder (except rats), small and large intestine, kidney, spleen, heart, brain, and quadriceps femoris muscle. Aliquots of all tissue samples were also stored at $-70{ }^{\circ} \mathrm{C}$ for RNA extraction.

\subsection{Inoculation of Animals with a Wild Boar Derived HEV-3 Strain}

\subsubsection{Inoculation of Mice}

In total, six wild-type (C57Bl/6) mice were inoculated concurrently via the oral and intravenous (i.v.) route, either with HEV positive liver homogenate $(n=2), \mathrm{HEV}$ positive feces suspension $(n=2)$, 
or PBS ( $n=2$, control group). The corresponding numbers were $1.8 \times 10^{6}$ copies in $250 \mu \mathrm{L}$ liver homogenate and $2.8 \times 10^{5}$ copies in $250 \mu \mathrm{L}$ feces suspension. According to the same scheme, four $\mathrm{CD}^{-/-}$and $4 \mathrm{CD}^{-/-}$mice were inoculated orally and intravenously with the same volumes of liver homogenate and of feces. Again, two PBS controls for each strain were included. In all three experimental setups, sampling time points were $0,1,4,7,10,12,14,17,19$, and $21 \mathrm{dpi}$ for feces, and 0 , $4,7,10,17$, and $21 \mathrm{dpi}$ for serum. At $21 \mathrm{dpi}$, all animals were necropsied.

IFNAR $^{-/}$mice were inoculated either orally (group 1, $n=3$ ) or i.v. (group 2, $n=3$ ) with liver homogenate $\left(1.8 \times 10^{6}\right.$ copies in $\left.250 \mu \mathrm{L}\right)$. For each inoculation group, one PBS control was added. Sampling time points for feces and serum were $0,3,7$, and 14 dpi regarding the oral group. Sampling (feces and serum) of the intravenous group occurred at 0, 2, 6, and 9 dpi. Necropsy was executed at 7 and 14 dpi (group 1) and 9 dpi (group 2), respectively.

Finally, a total number of 16 BALB/c nude (nu/nu) mice were inoculated i.v., either with $80 \mu \mathrm{L}$ HEV positive liver homogenate ( $5.8 \times 10^{5}$ copies), $80 \mu \mathrm{L}$ feces suspension $\left(8.8 \times 10^{4}\right.$ copies $), 80 \mu \mathrm{L}$ bile ( $2.3 \times 10^{5}$ copies), or $80 \mu \mathrm{L}$ PBS. In each case, groups of four animals were inoculated and co-habited with a single untreated mouse, respectively, which served as indicators of contact infection. Due to the small amounts, no RNA extraction was possible from the sampled serum. In general, inoculations were performed either by the injection of material into the lateral tail vein (Vena coccygea lateralis) and/or by applying material orally by gavage. Mice receiving sterile-filtered PBS $\left(0.22 \mu \mathrm{m}\right.$ MILLEX ${ }^{\circledR}$ GP filter unit) served as a negative control.

All animals were checked for clinical signs every day during the experiment, including the measurement of the body weight.

\subsubsection{Inoculation of Wistar Rats}

In the first experimental approach, eight rats were inoculated intravenously into the lateral tail vein (Vena coccygea lateralis), receiving $0.25 \mathrm{~mL}$ HEV positive liver suspension containing $1.8 \times 10^{6}$ copies and accordingly, eight rats serving as mock controls received $0.25 \mathrm{~mL}$ PBS. One additional rat was co-habited with the rats receiving HEV-3-containing liver suspension (total number of animals: 17). Feces was collected at $0,2,4,7,10,14,17,21,25,28$, and $32 \mathrm{dpi}$, and serum at $0,4,7,14,21$, and $32 \mathrm{dpi}$. At $4,7,14$, and 21 days post inoculation (dpi), two rats of each intravenously inoculated group were necropsied successively. The co-habited rat was euthanized at $32 \mathrm{dpi}$.

In a second approach, the potential influence of the immune status on infection dynamics and shedding was examined by pre-treatment of the 12 rats with dexamethasone $(0.15 \mathrm{mg} / \mathrm{kg}$, subcutaneously, Voren Suspension ${ }^{\circledR}$, Boehringer Ingelheim Vetmedica, Ingelheim, Germany) at days 7 , 4 , and 1 prior to inoculation. Eight rats simultaneously received $0.25 \mathrm{~mL}$ liver suspension intravenously and orally. Accordingly, four negative control rats received PBS. Sampling of feces was carried out at 0 , $2,4,7,14,17$, and $21 \mathrm{dpi}$, and serum at $0,4,7,14$, and $21 \mathrm{dpi}$. Two intravenously inoculated rats and one control rat, respectively, were subsequently necropsied at 4, 7, 14, and $21 \mathrm{dpi}$.

All animals were checked for clinical signs every day during the experiment, including the measurement of the body weight. Serum samples were analysed exclusively for serological analysis (ELISA).

\subsubsection{Inoculation of European Rabbits}

Two independent vaccination experiments were performed in European rabbits according to a standard immunization procedure: Initially, rabbits were immunized subcutaneously with $100 \mu \mathrm{g}$ antigen and complete Freund's adjuvant, followed by two consecutive boosts four and eight weeks dpi in incomplete Freund's adjuvant. Two weeks after the second boost, animals were inoculated correspondingly. In the first experiment (animal number: 3), one rabbit was immunized with an Escherichia coli expressed and purified His-tagged C-terminal segment of the ratHEV capsid protein (ratHEV-Ctr) prior to virus challenge [17]. Thereafter, the rabbit was inoculated intravenously into the ear vein (Vena auricularis), receiving $1.0 \mathrm{~mL}$ liver suspension containing $7.3 \times 10^{6}$ copies of the HEV-3 
genome. One non-vaccinated rabbit served as a positive control and was inoculated intravenously, receiving $1.0 \mathrm{~mL}$ liver suspension containing HEV-3 and accordingly, one rabbit received $1.0 \mathrm{~mL}$ PBS as a negative control. Feces and blood were sampled at consecutive time points $(0,1,3,5,7,11,14,18$, $21,26,28,32,35,40,42$, and 45 dpi) till necropsy (45 dpi).

In the second experiment (animal number: 4), two rabbits were immunized with an Escherichia coli expressed and purified His-tagged C-terminal segment of the HEV-3 capsid protein (GT3-Ctr) prior to virus challenge $[17,36]$. Four months later, the rabbits were inoculated intravenously, receiving $1.0 \mathrm{~mL}$ liver suspension containing HEV-3. One non-vaccinated rabbit receiving $1.0 \mathrm{~mL}$ liver suspension and one rabbit receiving 1.0 mL PBS served as positive and negative controls, respectively. Feces and blood samples were collected regularly $(0,1,3,5,7,11,14,19,21,25,28,31,34,39,42,45$, and 46 dpi) till necropsy (46 dpi).

\subsection{Anti-HEV Antibody ELISA and Quantitative Real-Time RT-PCR}

Sera were tested for the presence of total anti-HEV antibodies with a species independent HEV-Ab ELISA kit (Axiom, Bürstadt, Germany), according to the manufacturer's instructions. HEV RNA was detected by a novel diagnostic quantitative real-time RT-PCR assay (RT-qPCR) using the CFX96 ${ }^{\mathrm{TM}}$ Real-Time System (Bio-Rad Laboratories $\mathrm{GmbH}$, Munich, Germany), as described before [37]. Quantification of RNA was carried out by a standard curve using serial dilutions of an HEV standard (see Supplemental Figure S1). Copy number of the standards was calculated by a synthetic calibrator RNA encompassing the RT-qPCR amplicon and a 5' T-promotor sequence for in vitro transcription [37]. The limit of detection of about $1 \mathrm{cop} / \mu \mathrm{L}$ was reached at $\mathrm{Ct}$ values of $\sim 34$. As extraction and amplification control, an RT-qPCR amplifying a fragment of the beta-actin mRNA was performed for all samples [38].

\section{Results}

\subsection{Inoculation Experiments in Different Mouse Strains}

In a pilot study, different C57BL/ 6 mouse strains were tested for susceptibility to HEV-3. Therefore, groups of wild-type $(n=6)$, $\mathrm{IFNAR}^{-/-}(n=8), \mathrm{CD}^{-/-}(n=6)$, and $\mathrm{CD} 8^{-/-}(n=6)$ mice were inoculated intravenously and/or orally by HEV-3 positive liver or feces suspensions or PBS as a negative control. In a second approach with higher animal numbers per group, BALB/c nude mice $(n=16)$ were inoculated intravenously by liver, feces, or bile suspensions containing HEV-3 or PBS as a negative control. There was no evidence of a clinical disease in any of the challenged wild-type or immunodeficient mouse strains. The body weights remained within normal limits. In none of the inoculated mouse strains was HEV RNA detected in feces or tissue samples taken at necropsy. Additionally, the co-habited BALB/c nude mice $(n=4)$ had no clinical signs and did not shed the virus.

\subsection{Infection Trial in Dexamethasone Treated and Non-Treated Wistar Rats}

In a first experiment, eight Wistar rats were challenged with HEV-3 intravenously, while another eight rats were mock controls and one additional rat was a contact exposure control. None of the challenged rats showed clinical symptoms, and their body weights and rectal temperatures remained within normal limits. Anti-HEV antibodies were seen in two out of eight intravenously inoculated rats after $14\left(\mathrm{OD}_{450}: 2.9\right.$, cut-off: 0.19$)$ and $21 \mathrm{dpi}\left(\mathrm{OD}_{450}: 1.6\right.$, cut-off: 0.19$)$, and HEV RNA in feces was detectable in another rat at $7 \mathrm{dpi}(2.2$ copies per $\mu \mathrm{L})$. No viral RNA was found in the tissue of intravenously inoculated rats at necropsy ( $32 \mathrm{dpi}$ ). The contact animal did not seroconvert within the experiment, but viral RNA was found in the liver (4.4 copies per $\mu \mathrm{L}$ ). In a second experiment, eight dexamethasone-treated rats were simultaneously inoculated intravenously and orally to assess the influence of the immune status on infection dynamics and shedding. Four animals served as mock controls. A slight initial body weight decrease was observed in the dexamethasone-treated rats prior to the inoculation, which normalized during the challenge experiment. Neither feces nor tissue samples taken at necropsy tested positive for HEV RNA, and none of the animals showed detectable anti-HEV 
antibodies in serum. Moreover, negative controls remained seronegative within the experiment and viral RNA was not detected in any of the tissues and feces tested.

\subsection{Infection and Vaccination Trial in Rabbits}

In the first experiment, one rabbit was inoculated intravenously with liver homogenate containing HEV-3, one rabbit was immunized with a recombinant C-terminal fragment of the ratHEV capsid protein (ratHEV-Ctr) prior to the challenge, and another rabbit served as a negative control. Rabbits showed no clinical signs as the body weights and rectal temperatures remained within normal limits. The intravenously inoculated rabbit (rabbit 2) seroconverted within 28 dpi (Figure 1a). Viral RNA was detected in feces from 3 to $11 \mathrm{dpi}$, but not in tissue samples taken at necropsy ( $45 \mathrm{dpi}$ ), in contrast to the vaccinated and challenged rabbit (rabbit 3), where viral RNA was shed at 7 and $40 \mathrm{dpi}$; however, at very low copy numbers of about 3 and $1 \mathrm{cop} / \mu \mathrm{L}$ (Figure 1b). The mock-infected control (rabbit 1 ) remained negative during the course of the experiment. In the second approach, two rabbits (rabbits 6 and 7) were immunized with a recombinant C-terminal fragment of the HEV-3 capsid protein (GT3-Ctr) prior to the challenge (Figure 1b). The same experimental setup as described before was used for the control animals, i.e., one non-vaccinated rabbit (rabbit 5) was challenged intravenously and one non-vaccinated rabbit (rabbit 4) served as a mock control. Again, none of the animals showed any clinical symptoms. Seroconversion in the intravenously inoculated rabbit which was not vaccinated started after $28 \mathrm{dpi}$ and a slight booster effect was observed in the immunized inoculated rabbits at 14 to $25 \mathrm{dpi}$. Fecal RNA excretion was detected in the intravenously inoculated non-vaccinated rabbit from 3 to $42 \mathrm{dpi}$, but not in the immunized rabbits (Figure 1b). Moreover, HEV RNA was found in the liver and gall bladder of the intravenously inoculated non-vaccinated rabbit. In the immunized and challenged rabbits, viral RNA was not detectable in tissue upon necropsy. The mock controls were negative for anti-HEV antibodies or HEV RNA, respectively. In neither case could viral RNA be detected in serum samples.
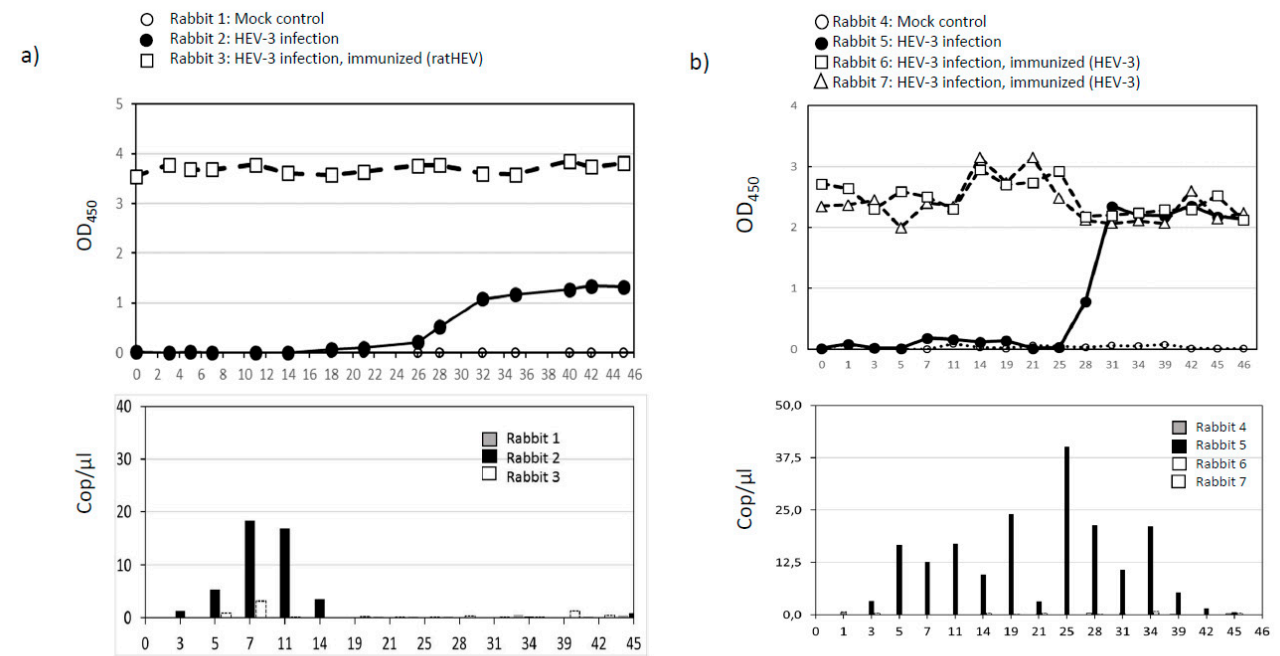

Figure 1. HEV-3 challenge of immunized and naïve European rabbits and induction of protective immunity by immunization with ratHEV capsid protein derivative (a) or HEV-3 capsid protein derivative (b). (a) Immunization with ratHEV capsid protein derivative (ratHEV-Ctr) and subsequent challenge with wild-boar derived HEV-3. [•] one non-vaccinated rabbit (Rabbit 2) inoculated with HEV-3; $[\square]$ rabbit 3 immunized with a C-terminal segment of ratHEV capsid protein derivative and inoculated with HEV-3 obtained from a wild boar liver; control [O] one rabbit (rabbit 1) inoculated with PBS (negative control). dpi = days post inoculation. (b) Immunization with HEV-3 capsid protein derivative (GT3-Ctr) and challenge with HEV-3. [•] one non-vaccinated rabbit (rabbit 5) inoculated with HEV-3; $[\Delta, \square]$ two rabbits (rabbits 6 and 7) immunized with a C-terminal segment of HEV-3 capsid protein and inoculated with HEV-3 obtained from a wild boar liver; control [○] one rabbit (rabbit 4) inoculated with PBS (negative control). 
Antibody responses to HEV in rabbit sera were measured by a double-antigen sandwich ELISA (given as optical density at $450 \mathrm{~nm}$, OD450) and fecal excretion of viral RNA was quantified by RT-qPCR (given as genome copies per $\mu \mathrm{L}$ RNA, cop $/ \mu \mathrm{L}$ ).

\section{Discussion}

Several types of animal models for HEV infection have been described previously [39,40]. In general, non-human-primates are the most suitable model animals as they can be infected with a variety of HEV genotypes. Domestic pigs have been successfully infected with HEV-3 and HEV-4, and represent a suitable large animal model for HEV infection $[36,41,42]$. However, primate and swine HEV infection models are quite complex and limited, so a small animal model for infection would be desirable. Thus far, laboratory mice, rats, and European rabbits have been explored as potential animal models for different HEV strains with diverging results [23,24,28,31,32], but it has not been resolved yet whether those species are also susceptible to an HEV-3 strain derived from wild boar.

In this study, an experimental HEV-3 infection of different C57BL/6 mouse strains (wild-type, $\left.\mathrm{IFNAR}^{-/-}, \mathrm{CD}^{-/}, \mathrm{CD}^{-/-}\right)$and BALB/c nude mice failed to suggest natural resistance to wild boar-derived HEV-3. In accordance with the results described here, $\mathrm{Li}$ et al. also failed to infect C57BL/6 mice with domestic pig-derived HEV-3, as well as with HEV-1 and HEV-4 strains [29]. In contrast, a former study showed that male BALB/c nude mice can be infected with an HEV-4 isolate derived from a domestic pig [28]. Unfortunately, the zygosity of the BALB/c nude mice in the previous study remained unclear, as we used homozygous mice. However, the discrepancy in the susceptibility of nude mice to HEV infection might also be due to gender effects (females in our study versus males in the former study).

RatHEV was frequently detected in rats of different species throughout the world [43], whereas HEV-3 was only reported in rats from the USA [44] and Japan [45]. Recently, a liver transplant recipient reported hepatitis caused by ratHEV infection [46]. A homologous challenge of Wistar rats using ratHEV resulted in virus replication and seroconversion [24]. Controversial data have been obtained for the susceptibility of rats to primate- and swine-derived HEV strains. Wistar rats could be experimentally infected with a human HEV strain of an unknown genotype in earlier studies [23]. Contrary, Wistar rats were resistant to intravenous inoculation of HEV-1 originating from a cynomolgus monkey, HEV-3 collected from a domestic pig, and a wild boar-derived HEV-4 strain [24]. In this study, HEV RNA and anti-HEV antibodies were detectable in a small portion of intravenously inoculated Wistar rats, pointing towards susceptibility to HEV-3 of wild boar origin. However, data indicate that Wistar rats might not represent a reliable animal model for HEV-3 infection. Interestingly, dexamethasone treatment in rats did not enhance the susceptibility to HEV infection, but resulted in the complete absence of seroconversion and RNA replication in all inoculated rats. Beside their main effects as immunosuppressants, treatments with glucocorticoids can have also immunostimulatory effects on the immune system. For example, glucocorticoids can prime NK cells for proinflammatory cytokine production [47]) and can also exert opposing effects on macrophage function, depending on their concentration [48]. Probably, similar immunostimulatory effects of dexamethasone might have accelerated virus clearance in our study. An in vitro study showed that dexamethasone treatment could also slow down virus replication of another RNA virus [49]. Hence, a longer observation period (>21 dpi) in our study would have been useful to detect late virus replication. Similarly, another group found no evidence that nude rats are susceptible to infection with HEV-3 [26], but ratHEV showed enhanced viral replication in these rats compared to immunocompetent rats [24].

Here, the experimental HEV-3 infection of European rabbits with a wild boar-derived strain led to seroconversion within four to five weeks post inoculation. Fecal virus shedding and HEV RNA in the liver and gall bladder could also be demonstrated. Our findings regarding the anti-HEV antibody responses are in accordance with another study in rabbits inoculated with HEV-3 [31], but in contrast to our results, viral replication could not be detected in this previous study. A similar study with a human HEV-3 strain again showed seroconversion, but no virus shedding in rabbits [50]. 
Since human-derived HEV-3 strains were used in these studies, it cannot be excluded that HEV-3 of wild boar origin replicates more efficiently in European rabbits. Moreover, the immunization of rabbits with an HEV-3 recombinant capsid protein derivative produced a robust anti-HEV antibody response and completely protected against HEV-3-challenge, as no HEV RNA was detected in feces and different tissue samples tested. To analyze the antigenic similarity of HEV-3 and ratHEV capsid protein derivatives and to evaluate potential cross protection, immunizations were performed with both antigens. Interestingly, ratHEV-derived capsid protein immunization resulted in a strong antibody response and almost complete protection against HEV-3 challenge. Only at two time points ( $7 \mathrm{dpi}$ and $40 \mathrm{dpi}$ ) were very low virus numbers shed to feces. A booster effect was seen in immunized animals two weeks post inoculation, indicative for antigen-specific memory B cells. In another study, HEV p179 vaccinated rabbits also produced high anti-HEV titers and were completely protected against challenge infection [31]. A more recent study indicated that HEV p239, another HEV vaccine candidate, is highly immunogenic in rabbits and provided complete protection of rabbits against homologous and heterologous HEV challenge [51]. Additionally, rabbits can be experimentally infected with HEV-4 originating from acute hepatitis E patients, but not with a human HEV-1 strain [31,32]. In this regard, it is of interest that HEV sequences of a human strain in France and rabbit strains were closely related, sharing a 93-nucleotide insertion within the ORF1 genomic region [11]. As recently shown, rabbit HEV, but not ratHEV, is able to infect domestic pigs in an experimental approach [34]. Interestingly, a study in China found no evidence of natural cross-species transmission of rabbit HEV between pigs and rabbits [51]. Although rabbit HEV belongs to the same genotype and serotype as human-derived HEV-3 [52,53], the antigenic relationship between rabbit HEV and the wild boar-derived HEV-3 used in this study remains unclear. Remarkably, we could also show that immunization with a recombinant ratHEV capsid protein derivative conveys cross-protection to HEV-3 challenge.

In conclusion, wild-type and immunodeficient mice are resistant to HEV-3 infection. HEV RNA and anti-HEV antibodies could be detected in rabbits and a portion of the rats inoculated, indicating a productive infection. A summary of experimental HEV infection is depicted in Figure 2. Simultaneous oral and intravenous HEV-3 inoculation did not enhance the susceptibility of dexamethasone-treated Wistar rats. Vaccination of rabbits with recombinant ratHEV and HEV-3 capsid protein derivatives protects against virus shedding after HEV-3 challenge. Contrary to mice and Wistar rats, European rabbits may serve as an alternative model for HEV-3 infection and as an appropriate basis for vaccine evaluation and antiviral drug testing studies.
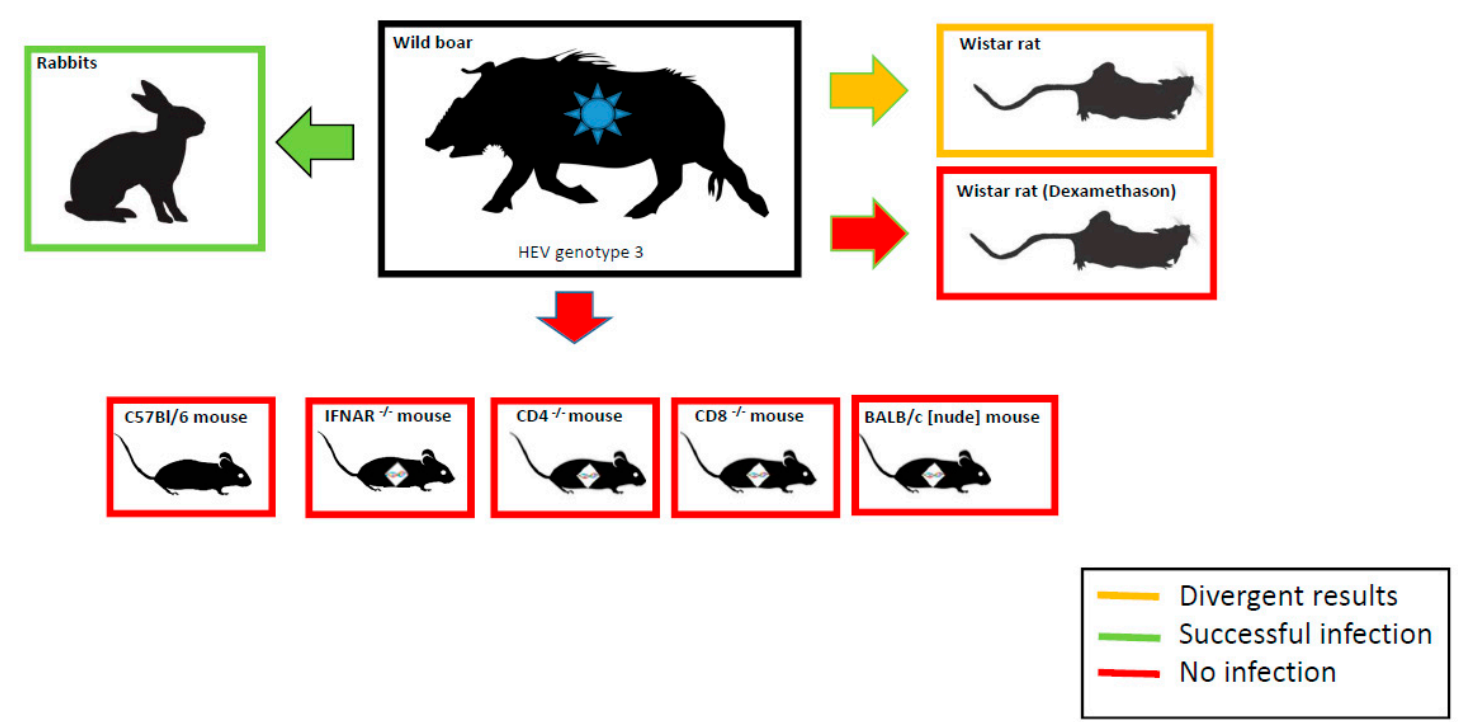

Figure 2. Experimental infection of wild boar-derived HEV-3 strain in wild-type and knockout mouse strains, Wistar rats, and rabbits. Details of the different experiments presented are given in the text. 
Supplementary Materials: Supplementary materials can be found at http:/ /www.mdpi.com/1999-4915/11/1/ $1 /$ s1.

Author Contributions: Conceived and designed the experiments: J.S., M.H.G., and M.E. Performed the experiments and necropsy: J.S., L.D., K.T., C.F., and U.Z. Analyzed the data: J.S., M.E., M.H.G., L.D., and P.D. Wrote the paper: J.S., R.G.U., A.G., M.H.G., and M.E. All authors read and approved the final manuscript. Data presented in this manuscript form part of the PhD thesis of J.S., completed at the University of Veterinary Medicine (Stiftung Tierärztliche Hochschule), Hannover, Germany.

Funding: This research received no external funding.

Acknowledgments: We thank Birke Boettcher and Gina Lucht for excellent technical assistance. The authors are grateful to Markus Keller for the contribution of the C57BL/6, IFNAR ${ }^{-/-}, \mathrm{CD}^{-/-}$, and CD8 ${ }^{-/-}$mouse strains from the SPF breeding unit of the Friedrich-Loeffler-Institut, Insel Riems. We would also like to thank all animal caretakers involved in this study for their excellent work. This study has been partly supported by the European Union funded project NADIR, by Deutsches Zentrum für Infektionsforschung (DZIF) and by the CSL Behring, Germany.

Conflicts of Interest: The authors declare that there is no conflict of interest.

\section{References}

1. Yin, X.; Ambardekar, C.; Lu, Y.; Feng, Z. Distinct Entry Mechanisms for Non enveloped and Quasi-Enveloped Hepatitis E Viruses. J. Virol. 2016, 28, 4232-4242. [CrossRef] [PubMed]

2. Emerson, S.U.; Purcell, R.H. Hepatitis E virus. Rev. Med. Virol. 2003, 13, 145-154. [CrossRef]

3. Tam, A.W.; Smith, M.M.; Guerra, M.E.; Huang, C.C.; Bradley, D.W.; Fry, K.E.; Reyes, G.R. Hepatitis E virus (HEV): Molecular cloning and sequencing of the full-length viral genome. Virology 1991, 185, 120-131. [CrossRef]

4. $\quad$ Emerson, S.U.; Purcell, R.H. Hepatitis E virus. Fields Virol. 2013, 2, 2242-2258. [CrossRef]

5. Ankcorn, M.J.; Tedder, R.S. Hepatitis E: The current state of play. Transfus. Med. 2017, 27, 84-95. [CrossRef]

6. Johne, R.; Dremsek, P.; Reetz, J.; Heckel, G.; Hess, M.; Ulrich, R.G. Hepeviridae: An expanding family of vertebrate viruses. Infect. Genet. Evol. 2014, 27, 212-229. [CrossRef] [PubMed]

7. Spahr, C.; Knauf-Witzens, T.; Vahlenkamp, T.; Ulrich, R.G.; Johne, R. Hepatitis E virus and related viruses in wild, domestic and zoo animals: A review. Zoonoses Public Health 2018, 65, 11-29. [CrossRef]

8. Purdy, M.A.; Harrison, T.J.; Jameel, S.; Meng, X.J.; Okamoto, H.; Van der Poel, W.H.M.; Smith, D.B. Ictv Report Consortium. ICTV Virus Taxonomy Profile: Hepeviridae. J. Gen. Virol. 2017, 98, 2645-2646. [CrossRef] [PubMed]

9. Cossaboom, C.M.; Cordoba, L.; Dryman, B.A.; Meng, X.J. Hepatitis E virus in rabbits, Virginia, USA. Emerg. Infect. Dis. 2011, 17, 2047-2049. [CrossRef] [PubMed]

10. Zhao, C.; Ma, Z.; Harrison, T.J.; Feng, R.; Zhang, C.; Qiao, Z.; Fan, J.; Ma, H.; Li, M.; Song, A.; et al. A novel genotype of hepatitis E virus prevalent among farmed rabbits in China. J. Med. Virol. 2009, 81, 1371-1379. [CrossRef]

11. Izopet, J.; Dubois, M.; Bertagnoli, S.; Lhomme, S.; Marchandeau, S.; Boucher, S.; Kamar, N.; Abravanel, F.; Guerin, J.L. Hepatitis E virus strains in rabbits and evidence of a closely related strain in humans, France. Emerg. Infect. Dis. 2012, 18, 1274-1281. [CrossRef]

12. Ryll, R.; Eiden, M.; Heuser, E.; Weinhardt, M.; Ziege, M.; Höper, D.; Groschup, M.H.; Heckel, G.; Johne, R.; Ulrich, R.G. Hepatitis E virus in feral rabbits along a rural-urban transect in Central Germany. Infect. Genet. Evol. 2018, 61, 155-159. [CrossRef]

13. Hammerschmidt, F.; Schwaiger, K.; Dähnert, L.; Vina-Rodriguez, A.; Höper, D.; Gareis, M.; Groschup, M.H.; Eiden, M. Hepatitis E virus in wild rabbits and European brown hares in Germany. Zoonoses Public Health 2017, 64, 612-622. [CrossRef] [PubMed]

14. Colson, P.; Borentain, P.; Queyriaux, B.; Kaba, M.; Moal, V.; Gallian, P.; Heyries, L.; Raoult, D.; Gerolami, R. Pig liver sausage as a source of hepatitis E virus transmission to humans. J. Infect. Dis. 2010, 202, 825-834. [CrossRef] [PubMed]

15. Matsuda, H.; Okada, K.; Takahashi, K.; Mishiro, S. Severe Hepatitis E Virus Infection after Ingestion of Uncooked Liver from a Wild Boar. J. Infect. Dis. 2003, 188, 944. [CrossRef]

16. Wichmann, O.; Schimanski, S.; Koch, J.; Kohler, M.; Rothe, C.; Plentz, A.; Jilg, W.; Stark, K. Phylogenetic and case-control study on hepatitis E virus infection in Germany. J. Infect. Dis. 2008, 198, 1732-1741. [CrossRef] 
17. Dremsek, P.; Wenzel, J.; Johne, R.; Ziller, M.; Hofmann, J.; Groschup, M.; Werdermann, S.; Mohn, U.; Dorn, S.; Motz, M.; et al. Seroprevalence study in forestry workers from eastern Germany using novel genotype 3and rat hepatitis E virus-specific immunoglobulin G ELISAs. Med. Microbiol. Immunol. 2012, 201, 189-200. [CrossRef]

18. Krumbholz, A.; Joel, S.; Dremsek, P.; Neubert, A.; Johne, R.; Durrwald, R.; Walther, M.; Muller, T.H.; Kuhnel, D.; Lange, J.; et al. Seroprevalence of hepatitis E virus (HEV) in humans living in high pig density areas of Germany. Med. Microbiol. Immunol. 2014, 203, 273-282. [CrossRef] [PubMed]

19. Nimgaonkar, I.; Ding, Q.; Schwartz, R.E.; Ploss, A. Hepatitis E virus: Advances and challenges. Nat. Rev. Gastroenterol. Hepatol. 2018, 15, 96-110. [CrossRef]

20. Kamar, N.; Izopet, J.; Pavio, N.; Aggarwal, R.; Labrique, A.; Wedemeyer, H.; Dalton, H.R. Hepatitis E virus infection. Nat. Rev. Dis. Primers. 2017, 3, 17086. [CrossRef]

21. Doceul, V.; Bagdassarian, E.; Demange, A.; Pavio, N. Zoonotic Hepatitis E Virus: Classification, Animal Reservoirs and Transmission Routes. Viruses 2016, 8, 270. [CrossRef]

22. Pavio, N.; Doceul, V.; Bagdassarian, E.; Johne, R. Recent knowledge on hepatitis E virus in Suidae reservoirs and transmission routes to human. Vet. Res. 2017, 48, 78. [CrossRef] [PubMed]

23. Maneerat, Y.; Clayson, E.T.; Myint, K.S.; Young, G.D.; Innis, B.L. Experimental infection of the laboratory rat with the hepatitis E virus. J. Med. Virol. 1996, 48, 121-128. [CrossRef]

24. Li, T.C.; Yoshizaki, S.; Ami, Y.; Suzaki, Y.; Yasuda, S.P.; Yoshimatsu, K.; Arikawa, J.; Takeda, N.; Wakita, T. Susceptibility of laboratory rats against genotypes 1, 3, 4, and rat hepatitis E viruses. Vet. Microbiol. 2013, 163, 54-61. [CrossRef]

25. Purcell, R.H.; Engle, R.E.; Rood, M.P.; Kabrane-Lazizi, Y.; Nguyen, H.T.; Govindarajan, S.; St Claire, M.; Emerson, S.U. Hepatitis E virus in rats, Los Angeles, California, USA. Emerg. Infect. Dis. 2011, 17, 2216-2222. [CrossRef]

26. Li, T.C.; Ami, Y.; Suzaki, Y.; Takeda, N.; Takaji, W. No evidence for hepatitis E virus genotype 3 susceptibility in rats. Emerg. Infect. Dis. 2013, 19, 1343-1345. [CrossRef]

27. Zhu, Y.; Yu, X.; Zhang, Y.; Ni, Y.; Si, F.; Yu, R.; Dong, S.; Huang, Y.; Li, Z. Infectivity of a genotype 4 hepatitis E virus cDNA clone by intrahepatic inoculation of laboratory rats. Vet. Microbiol. 2013, 166, 405-411. [CrossRef] [PubMed]

28. Huang, F.; Zhang, W.; Gong, G.; Yuan, C.; Yan, Y.; Yang, S.; Cui, L.; Zhu, J.; Yang, Z.; Hua, X. Experimental infection of Balb/c nude mice with Hepatitis E virus. BMC Infect. Dis. 2009, 9, 93. [CrossRef] [PubMed]

29. Li, T.C.; Suzaki, Y.; Ami, Y.; Tsunemitsu, H.; Miyamura, T.; Takeda, N. Mice are not susceptible to hepatitis E virus infection. J. Vet. Med. Sci. 2008, 70, 1359-1362. [CrossRef]

30. Allweiss, L.; Gass, S.; Giersch, K.; Groth, A.; Kah, J.; Volz, T.; Rapp, G.; Schöbel, A.; Lohse, A.W.; Polywka, S.; et al. Human liver chimeric mice as a new model of chronic hepatitis E virus infection and preclinical drug evaluation. J. Hepatol. 2016, 64, 1033-1040. [CrossRef] [PubMed]

31. Cheng, X.; Wang, S.; Dai, X.; Shi, C.; Wen, Y.; Zhu, M.; Zhan, S.; Meng, J. Rabbit as a novel animal model for hepatitis E virus infection and vaccine evaluation. PLoS ONE 2012, 7, e51616. [CrossRef] [PubMed]

32. Ma, H.; Zheng, L.; Liu, Y.; Zhao, C.; Harrison, T.J.; Ma, Y.; Sun, S.; Zhang, J.; Wang, Y. Experimental infection of rabbits with rabbit and genotypes 1 and 4 hepatitis E viruses. PLoS ONE 2010, 5, e9160. [CrossRef] [PubMed]

33. Han, J.; Lei, Y.; Liu, L.; Liu, P.; Xia, J.; Zhang, Y.; Zeng, H.; Wang, L.; Wang, L.; Zhuang, H. SPF rabbits infected with rabbit hepatitis E virus isolate experimentally showing the chronicity of hepatitis. PLoS ONE 2014, 9, e99861. [CrossRef]

34. Cossaboom, C.M.; Cordoba, L.; Sanford, B.J.; Pineyro, P.; Kenney, S.P.; Dryman, B.A.; Wang, Y.; Meng, X.J. Cross-species infection of pigs with a novel rabbit, but not rat, strain of hepatitis E virus isolated in the United States. J. Gen. Virol. 2012, 93, 1687-1695. [CrossRef]

35. Liu, P.; Bu, Q.N.; Wang, L.; Han, J.; Du, R.J.; Lei, Y.X.; Ouyang, Y.Q.; Li, J.; Zhu, Y.H.; Lu, F.M.; et al. Transmission of hepatitis E virus from rabbits to cynomolgus macaques. Emerg. Infect. Dis. 2013, 19, 559-565. [CrossRef]

36. Schlosser, J.; Eiden, M.; Vina-Rodriguez, A.; Fast, C.; Dremsek, P.; Lange, E.; Ulrich, R.G.; Groschup, M.H. Natural and experimental hepatitis E virus genotype 3 - infection in European wild boar is transmissible to domestic pigs. Vet. Res. 2014, 45, 121. [CrossRef] [PubMed] 
37. Vina-Rodriguez, A.; Schlosser, J.; Becher, D.; Kaden, V.; Groschup, M.H.; Eiden, M. Hepatitis E virus genotype 3 diversity: Phylogenetic analysis and presence of subtype $3 \mathrm{~b}$ in wild boar in Europe. Viruses 2015, 7, 2704-2726. [CrossRef]

38. Toussaint, J.F.; Sailleau, C.; Breard, E.; Zientara, S.; De Clercq, K. Bluetongue virus detection by two real-time RT-qPCRs targeting two different genomic segments. J. Virol. Methods 2007, 140, 115-123. [CrossRef]

39. Kenney, S.P.; Meng, X.J. Hepatitis E Virus: Animal Models and Zoonosis. Annu. Rev. Anim. Biosci. 2018. [CrossRef] [PubMed]

40. Li, T.C.; Wakita, T. Small Animal Models of Hepatitis E Virus Infection. Cold Spring Harb. Perspect. Med. 2018. [CrossRef] [PubMed]

41. Krawczynski, K.; Meng, X.J.; Rybczynska, J. Pathogenetic elements of hepatitis E and animal models of HEV infection. Virus Res. 2011, 161, 78-83. [CrossRef] [PubMed]

42. Schlosser, J.; Vina-Rodriguez, A.; Fast, C.; Groschup, M.H.; Eiden, M. Chronically infected wild boar can transmit genotype 3 hepatitis E virus to domestic pigs. Vet. Microbiol. 2015, 180, 15-21. [CrossRef] [PubMed]

43. Ryll, R.; Bernstein, S.; Heuser, E.; Schlegel, M.; Dremsek, P.; Zumpe, M.; Wolf, S.; Pépin, M.; Bajomi, D.; Müller, G.; et al. Detection of rat hepatitis E virus in wild Norway rats (Rattus norvegicus) and Black rats (Rattus rattus) from 11 European countries. Vet. Microbiol. 2017, 208, 58-68. [CrossRef] [PubMed]

44. Lack, J.B.; Volk, K.; Van Den Bussche, R.A. Hepatitis E virus genotype 3 in wild rats, United States. Emerg. Infect. Dis. 2012, 18, 1268-1273. [CrossRef]

45. Kanai, Y.; Miyasaka, S.; Uyama, S.; Kawami, S.; Kato-Mori, Y.; Tsujikawa, M.; Yunoki, M.; Nishiyama, S.; Ikuta, K.; Hagiwara, K. Hepatitis E virus in Norway rats (Rattus norvegicus) captured around a pig farm. BMC Res. Notes 2012, 5, 4. [CrossRef]

46. Sridhar, S.; Yip, C.C.Y.; Wu, S.; Cai, J.; Zhang, A.J.; Leung, K.H.; Chung, T.W.H.; Chan, J.F.W.; Chan, W.M.; Teng, J.L.L.; et al. Rat Hepatitis E Virus as Cause of Persistent Hepatitis after Liver Transplant. Emerg. Infect. Dis. 2018, 24, 2241-2250. [CrossRef]

47. Kim, M.S.; Lee, S.J.; Choi, S.H.; Kang, Y.J.; Kim, K.H. Dexamethasone treatment decreases replication of viral hemorrhagic septicemia virus in Epithelioma papulosum cyprini cells. Arch. Virol. 2017, 162, 1387-1392. [CrossRef] [PubMed]

48. Eddy, J.L.; Krukowski, K.; Janusek, L.; Mathews, H.L. Glucocorticoids regulate natural killer cell function epigenetically. Cell. Immunol. 2014, 290, 120-130. [CrossRef] [PubMed]

49. Lim, H.Y.; Müller, N.; Herold, M.J.; van den Brandt, J.; Reichardt, H.M. Glucocorticoids exert opposing effects on macrophage function dependent on their concentration. Immunology 2007, 122, 47-53. [CrossRef]

50. Zhang, Y.; Gong, W.; Song, W.T.; Fu, H.; Wang, L.; Li, M.; Wang, L.; Zhuang, H. Different susceptibility and pathogenesis of rabbit genotype 3 hepatitis E virus (HEV-3) and human HEV-3 (JRC-HE3) in SPF rabbits. Vet. Microbiol. 2017, 207, 1-6. [CrossRef]

51. Liu, P.; Du, R.; Wang, L.; Han, J.; Liu, L.; Zhang, Y.; Xia, J.; Lu, F.; Zhuang, H. Management of hepatitis E virus (HEV) zoonotic transmission: Protection of rabbits against HEV challenge following immunization with HEV 239 vaccine. PLoS ONE 2014, 9, e87600. [CrossRef] [PubMed]

52. Wang, S.; Cheng, X.; Dai, X.; Dong, C.; Xu, M.; Liang, J.; Dong, M.; Purdy, M.A.; Meng, J. Rabbit and human hepatitis E virus strains belong to a single serotype. Virus Res. 2013, 176, 101-106. [CrossRef] [PubMed]

53. Smith, D.B.; Simmonds, P.; Izopet, J.; Oliveira-Filho, E.F.; Ulrich, R.G.; Johne, R.; Koenig, M.; Jameel, S.; Harrison, T.J.; Meng, X.-J.; et al. Proposed reference sequences for Hepatitis E virus subtypes. J. Gen. Virol. 2016, 97, 537-542. [CrossRef] [PubMed]

(C) 2018 by the authors. Licensee MDPI, Basel, Switzerland. This article is an open access article distributed under the terms and conditions of the Creative Commons Attribution (CC BY) license (http:// creativecommons.org/licenses/by/4.0/). 